\title{
Sildenafil citrate in healthy and diseased hearts
}

\section{Seriki Samuel Adinoyi*}

Department of Human Physiology, College of Medical Sciences, Edo State University, Uzairue, Nigeria

\section{Abstract}

Sildenafil citrate is one of the frontline drugs used to manage erectile dysfunction (ED). Chemically, it is described as 1-[[3-(6,7-dihydro-1-methyl-7-oxo-3-propyl-1H -pyrazolo [4,3-d] pyrimidin-5-yl)-4 ethoxyphenyl] sulfonyl]-4-methylpiperazine citrate $\left(\mathrm{C}_{22} \mathrm{H}_{30} \mathrm{~N}_{6} \mathrm{O}_{4} \mathrm{~S}\right)$. It is a highly selective inhibitor of cyclic guanine monophosphate-specific phosphodiesterase type-5. There had been heightened concerns following reports that sildenafil citrate may increase the risk of cardiovascular events, particularly fatal arrhythmias, in patients with cardiovascular disease. So the cardiac electrophysiological effects of sildenafil citrate have been investigated extensively in both animal and clinical studies. This article ties up the various outcomes of the investigations with a view to guiding physicians and patients that use sildenafil citrate to manage erectile dysfunction, especially as it concerns its effect on their cardiovascular function in health and in disease. Sildenafil citrate could impact negatively on ailing hearts, but on a healthy heart, there may not be any such impact, rather, it improves on heart performance as it lowers the blood pressure.

\section{More Information}

*Address for Correspondence: Seriki Samuel Adinoyi, Department of Human Physiology, College of Medical Sciences, Edo State University, Uzairue, Nigeria, Tel: +2348036041121;

Email: seriki.adinoyi@gmail.com

Submitted: March 25, 2021

Approved: April 22, 2021

Published: April 23, 2021

How to cite this article: Adinoyi SS. Sildenafil citrate in healthy and diseased hearts. J Cardiol Cardiovasc Med. 2021; 6: 033-039.

\section{DOI: 10.29328/journal.jccm.1001115}

Copyright: @ 2021 Adinoyi SS. This is an open access article distributed under the Creative Commons Attribution License, which permits unrestricted use, distribution, and reproduction in any medium, provided the original work is properly cited.

Keywords: Sildenafil citrate; Erectile dysfunction; Cardiovascular function; Nitrate oxide; Myocardial infarction

\section{Check for updates}

OPEN ACCESS

\section{Introduction}

\section{Erectile dysfunction}

Erectile Dysfunction (ED) is a major health challenge across the world, prevalent among men of between 40 and 70 years, and indeed above 70 years. It is defined as the inability to achieve and/or maintain an erection sufficient for satisfactory sexual activity [1,2]. Incidentally, many men within this age range are predisposed to one cardiovascular disease or the other. It is considered to be a significant medical condition because it can lead to a loss of self-esteem, frustration, depression, and difficulty with disruption of sexual relationships [3].

\section{Sildenafil citrate}

Sildenafil citrate is a frontline drug approved for the treatment of erectile dysfunction (ED). It is phosphodiesterase type-5 (PDE5) inhibitor, relaxing blood vessels in the penis thereby facilitating erection. The inhibitor actually blocks the enzyme PDE5, which prevents relaxation of smooth muscle tissue.

There have been several claims of death associated with use of sildenafil citrate, especially among patients with history of cardiovascular diseases. This has therefore raised some concerns regarding its safety in patients with coronary artery disease [4].

\section{Heart and heart diseases}

The heart is a muscular pump that provides the force necessary to circulate the blood to all the tissues in the body. Its function is vital because, to survive, the tissues need a continuous supply of oxygen and nutrients, and metabolic waste products have to be removed. Deprived of these necessities, cells soon undergo irreversible changes that lead to death. While blood is the transport medium, the heart is the organ that keeps the blood moving through the vessels. The normal adult heart pumps about 5 liters of blood every minute throughout life. If it loses its pumping ability for even a few minutes, the individual's life is jeopardized (Figure 1).

\section{Heart disease}

Heart disease refers to various types of conditions that can affect heart function. These types include: Coronary artery (atherosclerotic) heart disease that affects the arteries to the heart; Valvular heart disease that affects how the valves function to regulate blood flow in and out of the heart. Cardiomyopathy that affects how the heart muscle squeezes; Heart rhythm disturbances (arrhythmias) that affect the electrical conduction; Heart infections where the heart has structural problems that develop before birth; Coronary artery disease is the most common type of heart disease. 


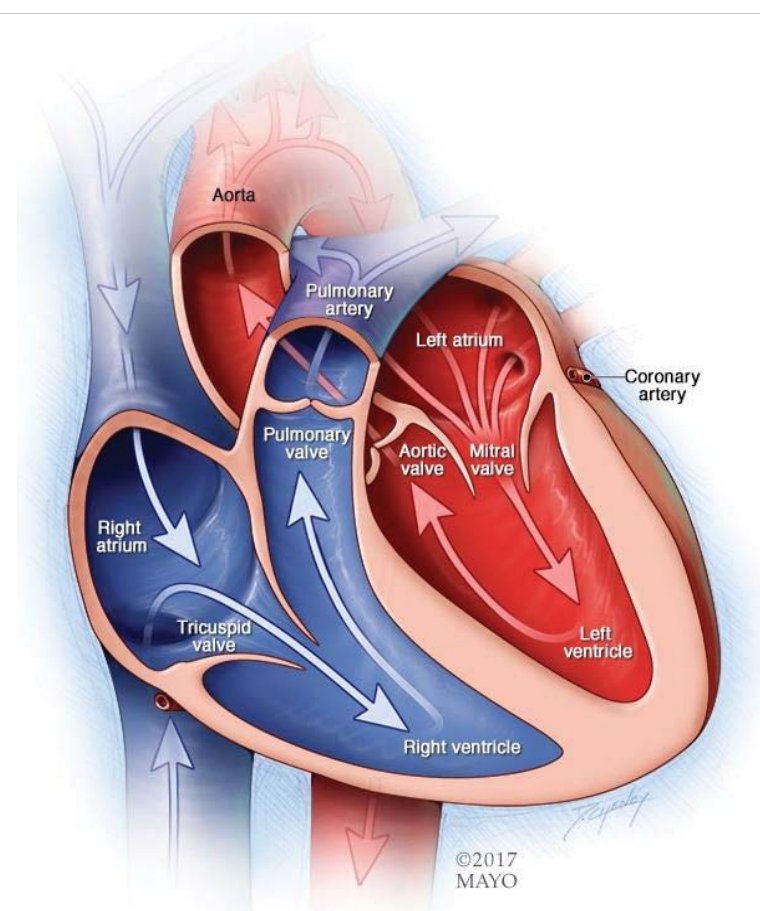

Figure 1: Diagram showing heart chambers and blood flow (Mayo Clinic acknowledged).

Coronary arteries supply blood to the heart muscle and coronary artery disease occurs when there is a buildup of cholesterol plaque inside the artery walls. Over time, this buildup of plaque may partially block the artery and decrease blood flow through it.

A heart attack occurs when a plaque ruptures and forms a clot in the artery causing a complete blockage. That part of the heart muscle that is denied blood supply starts to die.

Classic signs and symptoms of coronary heart disease may include: chest pain (angina) - this pain may radiate or move to the arm, neck, or back, shortness of breath, sweating, nausea, irregular heartbeat

Not all people with coronary artery disease have chest pain as a symptom. Some may have signs and symptoms of indigestion or exercise intolerance where they cannot perform activities that they normally once could.

Coronary heart disease is initially diagnosed by patient history and physical examination. EKG blood tests and tests to image the arteries and heart muscle confirm the diagnosis.

Treatment for coronary heart disease depends upon its severity. Many times lifestyle changes such as eating a heart-healthy diet, exercising regularly, stopping smoking, and controlling high blood pressure, high cholesterol, and diabetes may limit the artery narrowing. In some people, surgery or other procedures might be needed.

\section{Erectile dysfunction and cardiovascular disease}

ED is a common health concern among patients with cardiovascular disease. According to a research report, 34.8\% of men aged 40 to 70 years have moderate to complete ED, and $15 \%$ of men aged 70 have complete ED [3].

The risk of ED has been shown to increase with age, with a high prevalence of ED found in patients with cardiovascular disease [3]. A research report has shown a significant correlation between the severity of ED and the number of vessels involved in patients with coronary artery disease (CAD) [5].

The age-adjusted prevalence of complete ED has been reported to be 1.5 times higher in men with hypertension than in the entire population studied [3]. Epidemiologic studies have shown that ED shares important risk factors with coronary artery disease; they are both prevalent among smokers, diabetics and patients with hypercholesterolemia [6]. Another report also found that patients with CAD and peripheral vascular disease have an increased prevalence of ED [7].

\section{Sildenafil citrate and erectile dysfunction}

Seeing the frustration and consequent depression associated with erectile dysfunction, increasing attention has recently been given to it, especially with the advent of effective oral treatments [8]. Although ED was once diagnosed and treated primarily by urologists, primary healthcare physicians and other specialists such as cardiologists now write about $80 \%$ of the prescriptions for sildenafil citrate, the most popular drug used to treat this condition [9].

Sildenafil citrate is a frontline choice for the treatment of ED because it selectively inhibits phosphodiesterase type 5 (PDE-5) [10], which inactivates cyclic guanine monophosphate (cGMP), the mediator of smooth muscle relaxations in the corpus cavernosum. By selectively inhibiting cGMP catabolism in cavernosal smooth-muscle cells [10], sildenafil citrate can restore the natural erectile response to sexual stimulation without causing erections in the absence of such stimulation. It is rapidly absorbed, with maximal plasma concentrations occurring within an hour after oral administration and a mean terminal half-life of 3 to 5 hours [10]. So, sildenafil citrate has been shown to be an effective treatment for ED.

However, the report of several deaths reported in patients taking the drug in the 90 s raised the question as to whether the death was caused by the drug or triggered by an underlying disease such as ischemia, and not linked to a specific drug effect [11]. Nevertheless, the death reports raised concerns that sildenafil citrate may increase the risk of cardiovascular events in men with ED and cardiovascular disease [12], which led to many basic and clinical investigations of the adverse cardiovascular effects of the drug [12].

\section{Mechanism of action of Sildenafil citrate}

Sildenafil protectscyclicguanosine monophosphate (cGMP) 
from degradation by cGMP-specific phosphodiesterase type 5 (PDE5) in the corpus cavernosum. Nitric oxide (NO) in the corpus cavernosum of the penis binds to guanylate cyclase receptors, which results in increased levels of cGMP, leading to smooth muscle relaxation (vasodilation) of the intimal cushions of the helicine arteries. This smooth muscle relaxation leads to vasodilation and increased inflow of blood into the spongy tissue of the penis, causing an erection [13].

The molecular mechanism of smooth muscle relaxation involves the enzyme CGMP-dependent protein kinase, also known as PKG. This kinase is activated by cGMP and it phosphorylates multiple targets in the smooth muscle cells, namely myosin light chain phosphatase, RhoA, IP3 receptor, phospholipase C, and others [14]. Overall, this results in a decrease in intracellular calcium and desensitizing proteins to the effects of calcium, engendering smooth muscle relaxation [14].

Sildenafil is a potent and selective inhibitor of cGMP-specific phosphodiesterase type 5 (PDE5), which is responsible for degradation of cGMP in the corpus cavernosum. The molecular structure of sildenafil is similar to that of cGMP and acts as a competitive binding agent of PDE5 in the corpus cavernosum, resulting in more cGMP and increased penile response to sexual stimulation $[13,14]$. Without sexual stimulation, and therefore lack of activation of the NO/cGMP system, sildenafil should not cause an erection.

\section{Mechanism of metabolic sildenafil citrate}

Sildenafil is broken down in the liver by hepatic metabolism using cytochrome p450 enzymes, mainly CYP450 3A4 (major route), but also by CYP2C9 (minor route) hepatic isoenzymes. The major product of metabolisation by these enzymes is $\mathrm{N}$-desmethylated sildenafil, which is metabolized further. This metabolite also has an affinity for the PDE receptors, about $40 \%$ of that of sildenafil. Thus, the metabolite is responsible for about $20 \%$ of sildenafil's action. Sildenafil is excreted as metabolites predominantly in the feces (about $80 \%$ of administered oral dose) and to a lesser extent in the urine (around 13\% of the administered oral dose). If taken with a high-fat meal, absorption is reduced; the time taken to reach the maximum plasma concentration increases by around one hour, and the maximum concentration itself is decreased by nearly one-third [15].

\section{Use of sildenafil citrate in patients with cardiovascular disease}

Sildenafil citrate is a cGMP-specific PDE-5 inhibitor [10]. PDE-5, which is located primarily in the cavernous body, thrombocytes and vascular smooth muscle cells, degrades cGMP [16]. Thus, by inhibiting PDE-5, sildenafil citrate selectively increases cGMP levels [10]. It shows far less affinity for other phosphodiesterase isozymes, including PDE1 , which is abundant in ventricular myocytes [17]. However, concern about adverse cardiovascular effects remains [18] since PDE-5 inhibitors promote vasodilation, and thus has the potential to cause hypotension. This concern has been greatest for elderly patients with pre-existing cardiovascular disease. A review of the clinical database for this drug, which supports its cardiovascular safety in a wide range of patients abounds.

During placebo-controlled trials, the rate of myocardial infarction (MI) or cardiovascular death was 0.91 (95\% CI: 0.52-1.48) per 100 person-years (PY) of follow-up among sildenafil citrate-treated patients compared with 0.84 (95\% CI: 0.39-1.60) per 100 PY of follow-up among placebo-treated patients. The relative risk of MI or cardiovascular death was 1.08 (95\% CI: 0.45-2.77) for sildenafil citrate compared with placebo $(p=0.88)$. During open-label studies, the rate of MI or cardiovascular death was 0.56 (95\% CI: 0.44-0.72) per $100 \mathrm{PY}$ of follow-up. This analysis shows that rates of MI and cardiovascular death are low and comparable between men treated with sildenafil citrate and those treated with placebo, suggesting that the use of sildenafil citrate is not associated with an increase in the risk of MI or cardiovascular death [19].

Another study on male patients that were referred for coronary angiography with a diagnosis of chronic stable angina also revealed that sildenafil citrate is not associated with adverse cardiovascular effects. Hemodynamic measurements were taken during right and left heart catheterization in the basal state, and $60 \mathrm{~min}$ after $50 \mathrm{mg}$ of oral sildenafil. A single oral dose of sildenafil citrate had no significant hemodynamic effects in supine patients with stable angina [20]. This shows that isolated administration of sildenafil citrate does not appear to be associated with adverse cardiovascular effects.

\section{Hypotensive risk of Sildenafil citrate with patients on anti-hypertensive drugs}

It has been recommended that patients taking sildenafil citrate with combinations of antihypertensive drugs (such as calcium-channel blockers, ß-blockers, diuretics, and angiotensin-converting enzyme inhibitors) be alerted to the possibility of hypotension, particularly patients with congestive heart failure [21]. Therefore, patients with wellcontrolled hypertension can be safely managed with approved medical treatments for ED [12]. However, concomitant use of nitrates is considered to be an absolute contraindication for the use of sildenafil citrate to avoid the risk of hypotension [22].

\section{Nitrites}

Nitrates are prescribed in several different forms, including sublingual nitroglycerin, oral isosorbide mononitrate or dinitrate, nitropatch, and nitropaste, all of which have been associated with a prolonged decrease in blood pressure when used concomitantly with sildenafil citrate [22].

They are metabolized in vessel walls, where they release nitric oxide. Sildenafil citrate prolongs the vasodilatory 
effects of nitrates by decreasing the breakdown of nitric oxide's main effector, cGMP. It is not sure how much time must elapse between administration of sildenafil citrate and administration of nitrates to avoid significant hypotensive effects [22], but it has been suggested to assume an interval of at least 24 hrs [22]. Nitroprusside also causes vasodilatation by non-enzymatic release of nitric oxide, and thus is predicted to have a synergistic hypotensive effect with sildenafil citrate [22].

Effects of sildenafil citrate on cardiac contractility, blood pressure and heart rate

Sildenafil citrate belongs to a class of compounds called PDE inhibitors. PDEs comprise a diverse family of enzymes that hydrolyze cyclic nucleotides (cAMP and cGMP) and therefore play a critical role in the modulation of second messenger signaling pathways [16]. Sildenafil citrate is an inhibitor that is about 4,000 times highly selective of human PDE-5 over human PDE-3 [22]. This is important because inhibitors of PDE-3 (the isozyme involved in the regulation of cardiac contractility), such as milrinone, vesnarinone and enoximone, which have been used in patients with heart failure, are generally associated with an increased incidence of cardiac arrhythmias and other serious side effects [23]. The cardiotoxic effects of PDE-3 inhibitors are thought to be related to an increase in intracellular cAMP in the myocardium $[24,25]$. However, PDE-5 is not present in cardiac myocytes [25]. Corbin and colleagues [26] demonstrated in both dog and human hearts that sildenafil citrate was unlikely to directly produce an inotropic effect on cardiac muscle.

Systemic and pulmonary arterial and venous smooth muscle cells contain PDE-5. However, sildenafil citrate causes only a mild and transient decrease in blood pressure (8-10 mmHg for systolic blood pressure and 5-6 mmHg for diastolic blood pressure) [19]. The peak effects are evident $1 \mathrm{~h}$ after the dose is given and last for approximately $4 \mathrm{~h}$ [19]. Heart rate and cardiac output are not significantly affected. Along with a mild decrease in systemic vascular resistance and afterload, there is also a mild decrease in preload and stroke volume due to venous vasodilatation. These effects are not dependent upon age or dose (within the range of 25 to $800 \mathrm{mg}$ ) [25]. In a study of patients with severe coronary artery disease, it has been confirmed that the hemodynamic effects of sildenafil citrate (when taken alone) are not associated with clinically significant hypotension [27\}.

Effects of sildenafil citrate on central hemodynamics and peripheral vasculature

In normal volunteers, no significant changes in cardiac index were evident up to $12 \mathrm{~h}$ after administration of oral sildenafil citrate (100 to $200 \mathrm{mg}$ ) or intravenous sildenafil citrate (20 to $80 \mathrm{mg}$ ) [25]. Significant decreases in the systemic vascular resistance index were reported at the end of intravenous sildenafil citrate infusion (20 to $80 \mathrm{mg}$ ), when plasma concentrations were highest [25]. Sildenafil citrate has both vasodilator and venodilator effects on the peripheral vasculature [25]. In 8 patients with stable angina, intravenous sildenafil citrate reduced systemic and pulmonary arterial pressures, as well as cardiac output, by 8,25 , and $7 \%$, respectively, consistent with its mixed arterial (systemic and pulmonary hypotension) and venous (drop in stroke volume secondary to decreased preload) vasodilator effects [28].

Although the therapeutic efficacy of sildenafil citrate in the treatment of ED has been proven, little is known about the potential beneficial effects of sildenafil citrate in other diseases. Studies in rats demonstrated that PDE-5 inhibition with sildenafil attenuates the rise in pulmonary artery pressure and vascular remodeling when given before chronic exposure to hypoxia-induced pulmonary hypertension [29] Likewise, clinical investigations in patients with pulmonary arterial hypertension have shown that sildenafil citrate therapy may be beneficial to patients receiving long-term infusion of epoprostenol [30,31]. A recent meta-analysis study has suggested that the validity of the observed effect of sildenafil on pulmonary hypertension is not conclusive due to small participant numbers and inadequate investigation of different disease etiologies. In addition, further studies are needed to investigate the long-term outcome [32].

\section{Cardiac electrophysiological effects of sildenafil citrate}

In the past few years, the cardiac electrophysiological effects of sildenafil citrate have been investigated extensively [33]. Geelen and colleagues [33] demonstrated that sildenafil citrate induces a dose-dependent block of the rapid component of the delayed rectifier potassium current $\left(I_{\mathrm{Kr}}\right)$. They also reported that sildenafil citrate can have an action similar to that of class III antiarrhythmic drugs [33]. These effects are observed at concentrations that may be found in conditions of impaired drug elimination such as renal or hepatic insufficiency, during co-administration of another CYP3A4 inhibitor, or after drug overdose [11]. Prolonged cardiac repolarization caused by sildenafil citrate could result in malignant ventricular arrhythmias and lead to sudden cardiac death in some of these patients [11]. Swissa and colleagues [34] demonstrated that a combination of sildenafil citrate and a nitric oxide donor increases ventricular tachyarrhythmia/ VF vulnerability in the normal right ventricle of swine.

Although many reports have demonstrated the arrhythmogenic effects of sildenafil citrate, some studies have reported otherwise. Vardi and colleagues [35] showed that sildenafil citrate does not alter the hemodynamic responses to exercise or change the incidence of ventricular arrhythmias in men with cardiovascular disease and ED. Chiang and colleagues [36] found that sildenafil citrate at concentrations up to $30 \mu \mathrm{M}$ has no significant effect on either the rapid $\left(I_{\mathrm{Kr}}\right)$ or the slow $\left(I_{\mathrm{Ks}}\right)$ components of the delayed rectifier potassium currents in guinea pig ventricular myocytes. They also found that sildenafil citrate dose-dependently blocks 
L-type $\mathrm{Ca}^{2+}$ currents $\left(I_{\mathrm{Ca}, \mathrm{L}}\right)$, but has no effect on persistent $\mathrm{Na}^{+}$currents. They concluded that sildenafil citrate does not prolong cardiac repolarization. Instead, in supra-therapeutic concentrations, it accelerates cardiac repolarization, presumably via its blocking effect on $I_{\mathrm{Ca}, \mathrm{L}}$ [36]. Recent studies have also demonstrated that oral administration of $50 \mathrm{mg}$ sildenafil citrate does not affect QT dynamic properties [37]. Furthermore, Nagy and colleagues [38] recently reported that sildenafil citrate reduces arrhythmia severity during ischemia $24 \mathrm{~h}$ after oral administration in dogs.

\section{Cardioprotective effects of sildenafil citrate}

Ischemic preconditioning often results in powerful cardioprotective effects [39]. Repeated brief episodes of ischemia initiate a cascade of intracellular signaling events which help prevent future myocardial infraction and stunning [39]. After initial observation, this phenomenon, termed "myocardial preconditioning, was studied intensively to try to understand its cellular mechanisms and apply this knowledge towards protection of the human heart from ischemic heart disease. Current data suggest that sildenafil citrate has a preconditioning-like cardioprotective effect in the rabbit, rat and mouse heart [40]. Das and colleagues [41] reported that sildenafil citrate at a much lower dose $(0.05 \mathrm{mg} / \mathrm{kg})$ provides significant cardioprotection in isolated perfused rat hearts following global ischemic-reperfusion. They observed an improved post-ischemic recovery of ventricular function, a reduction in the incidence of VF, and a decrease in MI. At higher doses, sildenafil caused a significant increase in the incidence of VF, while at very low doses it had no effect on cardiac function [41]. However, a study by Reffelmann and Kloner [42] demonstrated otherwise. In their report, they did not find a decrease in myocardial necrosis following ischemia-reperfusion in a rabbit model. The reason for these negative results was not clear. The only noticeable difference in the experimental procedure was a considerably longer drug infusion time ( $\sim 5 \mathrm{~min}$ ) in the study by Reffelmann and Kloner [42] as compared to that used by Ockaili and colleagues [42] ( $\sim 1 \mathrm{~min}$ ), which could potentially affect the hemodynamic response prior to ischemia.

\section{Signaling mechanisms in sildenafil-induced cardio- protection}

Although sildenafil citrate has been shown to have a powerful preconditioning-like cardioprotective effects in animal models of ischemia-reperfusion injury, the precise cellular mechanism underlying these effects remains yet unclear. The sildenafil citrate-induced cardioprotective effect against ischemia-reperfusion injury is dependent upon the opening of mitochondrial ATP-sensitive potassium channels (mitoK $_{\text {ATP }}$ channels) in rabbits [43]. It has been proposed that the vasodilatory action of sildenafil citrate could potentially cause the release of endogenous mediators of preconditioning, such as adenosine or bradykinin from endothelial cells, which may trigger a signaling cascade (through the action of kinases) and the release of nitric oxide [43]. Generation of nitric oxide could potentially activate guanylate cyclase, resulting in an enhanced formation of cGMP [44]. cGMP may activate protein kinase $\mathrm{G}$, which could then open mitoK $\mathrm{ATP}_{\text {channels, resulting }}$ in both acute and delayed cardioprotective effects [45]. Mitochondria are known to play an essential role in cell survival via ATP synthesis and maintenance of $\mathrm{Ca}^{2+}$ homeostasis [46]. Opening mitoK $\mathrm{K}_{\text {AтP }}$ channels partially compensates the membrane potential, which enables additional protons to be pumped out to form an $\mathrm{H}^{+}$electrochemical gradient to drive both ATP synthesis and $\mathrm{Ca}^{2+}$ transport. Recently, it was reported that protein kinase $\mathrm{C}$ also plays an essential role in sildenafil-induced cardioprotection in rabbits [47].

\section{Conclusion}

Going by the extensive data available to date, sildenafil citrate has been shown to pose minimal cardiovascular risks to healthy people taking this drug. Some precautions, however, are needed for patients with cardiovascular disease, particularly as it concerns patients treating CVD with nitrites. This is because PDE-5 inhibitors promote vasodilation, and thus has the potential to cause hypotension. This concern has been greatest for elderly patients with pre-existing cardiovascular disease. Therefore doctors managing ED with sildenafil citrate must first be sure that the patient does not have a CVD or managing any cardiovascular disease with nitrites.

It is also evident that sildenafil may have some cardioprotective effect on healthy hearts via some complex cell signaling pathway. Vasodilatory action of sildenafil citrate could potentially cause the release of endogenous mediators of preconditioning, such as adenosine or bradykinin from endothelial cells, which may trigger a signaling cascade (through the action of kinases) and the release of nitric oxide. The nitric oxide so released could potentially activate guanylate cyclase, resulting in an enhanced formation of cGMP. The cGMP may activate protein kinase G, which could then open mitoK ${ }_{\text {ATP }}$ channels, resulting in both acute and delayed cardioprotective effects. Further clinical and basic investigation on the cardiovascular effects of sildenafil citrate in this regard will help the world of knowledge.

\section{References}

1. Chew KK, Earle CM, Stuckey BG, Jamrozik K, Keogh EJ. Erectile dysfunction in general medicine practice: prevalence and clinical correlates. Int J Impotence Res. 2000; 12: 41-45.

PubMed: https://pubmed.ncbi.nlm.nih.gov/10982311/

2. Laumann EO, Paik A, Rosen RC. Sexual dysfunction in the United States: prevalence and predictors. J Am Med Assoc. 1999; 281:537-544. PubMed: https://pubmed.ncbi.nlm.nih.gov/10022110/

3. Feldman HA, Goldstein I, Hatzichristou DG, Krane RJ, McKinlay JB. Impotence and its medical and psychosocial correlates: results of the Massachusetts Male Aging Study. J Urol. 1994; 151: 54-61. PubMed: https://pubmed.ncbi.nlm.nih.gov/8254833/

4. Kloner RA. Cardiovascular risk and sildenafil. Am J Cardiol. 2000; 86: 57F-61F PubMed: https://pubmed.ncbi.nlm.nih.gov/10899281/ 
5. Greenstein A, Chen J, Miller H, Matzkin H, Villa Y, et al. Does severity of ischemic coronary disease correlate with erectile function? Int J Impotence Res.1997; 9: 123-126.

6. Israilov S, Baniel J, Shmueli J, Niv E, Engelstein D, et al. Treatment program for erectile dysfunction in patients with cardiovascular diseases. Am J Cardiol. 2004; 93: 689-693.

7. Khan MA, Ledda A, Mikhailidis DP, Rosano G, Vale J, et al. Second Consensus Conference on Cardiovascular Risk Factors and Erectile Dysfunction. Curr Med Res Opinion. 2002; 18: 33-35.

8. Lue TF. Erectile dysfunction. New Engl J Med. 2000; 342: 1802-1813. PubMed: https://pubmed.ncbi.nlm.nih.gov/10853004/

9. Kloner RA, Jarow JP. Erectile dysfunction and sildenafil citrate and cardiologists. Am J Cardiol. 1999; 83: 576-582.

PubMed: https://pubmed.ncbi.nlm.nih.gov/10073864/

10. Goldstein I, Lue TF, Padma-Nathan H, Rosen RC, Steers WD, et al. Oral sildenafil in the treatment of erectile dysfunction. Sildenafil Study Group. New Engl J Med. 1998; 338: 1397-1404.

PubMed: https://pubmed.ncbi.nlm.nih.gov/9580646/

11. Shakir SA, Wilton LV, Boshier A, Layton D, Heeley E. Cardiovascular events in users of sildenafil: results from first phase of prescription event monitoring in England. Bri Med J. 2001; 322: 651-652.

12. DeBusk R, Drory Y, Goldstein I. Management of sexual dysfunction in patients with cardiovascular disease: recommendations of the Princeton Consensus Panel. Am J Cardiol. 2000; 86: 62F-68F. PubMed: https://pubmed.ncbi.nlm.nih.gov/10899282/

13. Webb DJ, Freestone S, Allen MJ, Muirhead GJ. Sildenafil citrate and blood-pressure-lowering drugs: results of drug interaction studies with an organicnitrateandacalciumantagonist. AmJCardiol.1999;83:21C-28C. PubMed: https://pubmed.ncbi.nlm.nih.gov/10078539/

14. Francis SH, Busch JL, Corbin JD, Sibley D. cGMP-dependent protein kinases and cGMP phosphodiesterases in nitric oxide and cGMP action. Pharmacol Rev. 2010; 62: 525563.

PubMed: https://www.ncbi.nlm.nih.gov/pmc/articles/PMC2964902/

15. Viagra Clinical Pharmacology. 2008. RxList.com

16. Beavo JA. Cyclic nucleotide phosphodiesterases: functional implications of multiple isoforms. Physiol Rev. 1995; 75: 725-748. PubMed: https://pubmed.ncbi.nlm.nih.gov/7480160/

17. Wallis RM, Corbin JD, Francis SH, Ellis P. Tissue distribution of phosphodiesterase families and the effects of sildenafil on tissue cyclic nucleotides, platelet function, and the contractile responses of trabeculae carneae and aortic rings in vitro. Am J Cardiol. 1999; 83: 3C-12C. PubMed: https://pubmed.ncbi.nlm.nih.gov/10078537/

18. Arora RR, Timoney M, Melilli L. Acute myocardial infarction after the use of sildenafil. New Engl J Med.1999; 341: 700

19. Mittleman MA, Glasser DB, Orazem J. Clinical trials of sildenafil citrate (Viagra) demonstrate no increase in risk of myocardial infarction and cardiovascular death compared with placebo. Int J Clin Pract. 2003; 57: $597-600$

PubMed: https://pubmed.ncbi.nlm.nih.gov/14529061/

20. Manfroi WC, Caramori PR, Zago AJ, Melchior R, Zen V, et al. Hemodynamic effects of sildenafil in patients with stable ischemic heart disease. Int J Cardiol. 2003: 90: 153-157.

21. Cheitlin MD, Hutter Jr AM, Brindis RG, Ganz P, Kaul S, et al. Use of sildenafil (Viagra) in patients with cardiovascular disease. Technology and Practice Executive Committee. Circulation.1999; 99: 168-177. PubMed: https://pubmed.ncbi.nlm.nih.gov/9884398/

22. Cheitlin MD, Hutter Jr AM, Brindis RG, Ganz P, Kaul S, et al. ACC/AHA expert consensus document. Use of sildenafil (Viagra) in patients with cardiovascular disease. American College of Cardiology/American Heart Association. J Am College Cardiol. 1999; 33: 273-282.

PubMed: https://pubmed.ncbi.nlm.nih.gov/9935041/
23. Packer M, Carver JR, Rodeheffer RJ, Ivanhoe RJ, DiBianco R, et al Effect of oral milrinone on mortality in severe chronic heart failure. The Promise Study Research Group. New Engl J Med. 1991; 325: 1468-1475. PubMed: https://pubmed.ncbi.nlm.nih.gov/1944425/

24. Degerman E, Belfrage P, Manganiello VC. Structure, localization, and regulation of CGMP-inhibited phosphodiesterase (PDE3). J Biol Chem. 1997; 272: 6823-6826.

PubMed: https://pubmed.ncbi.nlm.nih.gov/9102399/

25. Nony P, Boissel JP, Lievre M, Leizorovicz A, Haugh MC, et al. Evaluation of the effect of phosphodiesterase inhibitors on mortality in chronic heart failure patients. Ameta-analysis. EurJClinPharmacol. 1994;46:191-196. PubMed: https://pubmed.ncbi.nlm.nih.gov/8070498/

26. Corbin J, Rannels S, Neal D, Chang P, Grimes K, et al. Sildenafil citrate does not affect cardiac contractility in human or dog heart. Curr Med Res Opinion. 2003; 19: 747-752.

27. Herrmann HC, Chang G, Klugherz BD, Mahoney PD. Hemodynamic effects of sildenafil in men with severe coronary artery disease. New Engl J Med. 2000; 342: 1622-1626. PubMed: https://pubmed.ncbi.nlm.nih.gov/10833207/

28. Rajfer J, Aronson WJ, Bush PA, Dorey FJ, Ignarro LJ. Nitric oxide as a mediator of relaxation of the corpus cavernosum in response to nonadrenergic, noncholinergic neurotransmission. New Eng J Med. 1992; 326: 90-94

PubMed: https://pubmed.ncbi.nlm.nih.gov/1309211/

29. Sebkhi A, Strange JW, Phillips SC, Wharton J, Wilkins MR. Phosphodiesterase type 5 as a target for the treatment of hypoxiainduced pulmonary hypertension. Circulation. 2003; 107: 3230-3235. PubMed: https://pubmed.ncbi.nlm.nih.gov/12796132/

30. Stiebellehner L, Petkov V, Vonbank K, Funk G, Schenk P, et al. Long-term treatment with oral sildenafil in addition to continuous IV epoprostenol in patients with pulmonary arterial hypertension. Chest. 2003; 123: 1293-1295.

PubMed: https://pubmed.ncbi.nIm.nih.gov/12684325/

31. Wilkens H, Guth A, Konig J, Forestier N, Cremers B, et al. Effect of inhaled iloprost plus oral sildenafil in patients with primary pulmonary hypertension. Circulation. 2001; 104: 1218-1222.

PubMed: https://pubmed.ncbi.nlm.nih.gov/11551870/

32. Kanthapillai $P$, Lasserson $T$, Walters E. Sildenafil for pulmonary hypertension. Cochrane Database of Syst Rev. 2004; CD003562. PubMed: https://www.ncbi.nlm.nih.gov/pmc/articles/PMC6396057/

33. Geelen P, Drolet B, Rail J, Berube J, Daleau P, et al. Sildenafil (Viagra) prolongs cardiac repolarization by blocking the rapid component of the delayed rectifier potassium current. Circulation. 2002; 102: 275-277.

34. Swissa M, Ohara T, Lee MH, Kaul S, Shah PK, et al. Sildenafil-nitric oxide donor combination promotes ventricular tachyarrhythmias in the swine right ventricle. Am J Physiol. 2002; 282: H1787-H1792.

35. Vardi $Y$, Bulus M, Reisner S, Nassar S, Aboud L, et al. Effects of sildenafil citrate (Viagra) on hemodynamic parameters during exercise testing and occurrence of ventricular arrhythmias in patients with erectile dysfunction and cardiovascular disease. Eur Urol. 2003; 43: 544-551.

36. Chiang CE, Luk HN, Wang TM, Ding PY. Effects of sildenafil on cardiac repolarization. Cardiovasc Res. 2002; 55: 290-299.

37. Kaya D, Guler C, Esen AM, Barutcu I, Dincel C. Sildenafil citrate does not alter ventricular repolarization properties: novel evidence from dynamic QT analysis. Ann Noninvasive Electrocardiol. 2004; 9: 228-233. PubMed: https://www.ncbi.nlm.nih.gov/pmc/articles/PMC6932561/

38. Nagy O, Hajnal A, Parratt JR, Vegh A. Sildenafil (Viagra) reduces arrhythmia severity during ischaemia $24 \mathrm{~h}$ after oral administration in dogs. Br J Pharmacol. 2004; 141: 549-551. PubMed: https://pubmed.ncbi.nlm.nih.gov/14744808/

39. Murry CE, Jennings RB, Reimer KA. Preconditioning with ischemia: a delay of lethal cell injury in ischemic myocardium. Circulation. 1986; 74: 1124-1136.

PubMed: https://pubmed.ncbi.nlm.nih.gov/3769170/ 
40. Salloum F, Yin C, Xi L, Kukreja RC. Sildenafil induces delayed preconditioning through inducible nitric oxide synthase-dependent pathway in mouse heart. Circulat Res. 2003; 92: 595-597.

PubMed: https://pubmed.ncbi.nlm.nih.gov/12637371/

41. Das S, Maulik N, Das DK, Kadowitz PJ, Bivalacqua TJ. Cardioprotection with sildenafil, a selective inhibitor of cyclic 3',5'-monophosphatespecific phosphodiesterase 5. Drugs under Experimen Clin Res. 2002; 28: 213-219.

PubMed: https://pubmed.ncbi.nlm.nih.gov/12776574/

42. Reffelmann T, Kloner RA. Effects of sildenafil on myocardial infarct size, microvascular function, and acute ischemic left ventricular dilation. Cardiovasc Res. 2003; 59: 441-449.

PubMed: https://pubmed.ncbi.nlm.nih.gov/12909327/

43. Ockaili R, Salloum F, Hawkins J, Kukreja RC. Sildenafil (Viagra) induces powerful cardioprotective effect via opening of mitochondrial
K(ATP) channels in rabbits. Am J Physiol. 2002; 283: H1263-H1269. PubMed: https://pubmed.ncbi.nlm.nih.gov/12181158/

44. Wallis RM. The pharmacology of sildenafil, a novel and selective inhibitor of phosphodiesterase (PDE) type 5. Nippon Yakurigaku Zasshi. Japanese J Pharmacol. 1999; 114: 22P-26P.

45. Zhao TC, Kukreja RC. Late preconditioning elicited by activation of adenosine $\mathrm{A}(3)$ receptor in heart: role of NF-kappa B, iNOS and mitochondrial K(ATP) channel. J Mole Cell Cardiol. 2002; 34: 263-277.

46. Gross GJ. The role of mitochondrial KATP channels in cardioprotection. Basic Res Cardiol. 2000; 95: 280-284.

47. Das A, Ockaili R, Salloum F, Kukreja RC. Protein kinase C plays an essential role in sildenafil-induced cardioprotection in rabbits. Am J Physiol. 2004; 286: H1455-H1460.

PubMed: https://pubmed.ncbi.nlm.nih.gov/15020304/ 